PRINT ISSN 1119-8362

Electronic ISSN 1119-8362
Full-text Available Online at https://www.ajol.info/index.php/jasem http://ww.bioline.org.br/ja
J. Appl. Sci. Environ. Manage.

Vol. 25 (5) 807-814 May 2021

\title{
Therapeutic Artemether-Lumefantrine Modulated Monosodium Glutamate-Related Adversity on Rats' Kidney Histology and Antioxidant Response Bio-Indicators
}

\author{
"EGBUONU, ACC; ALAEBO, PO; CHUKWU, CN; UWANDU, DDC; ORJI, IM; \\ UZOECHI, JC; NWUKE, CP \\ Department of Biochemistry, Michael Okpara University of Agriculture, Umudike, Abia State, Nigeria \\ *Corresponding author's email: tonycemalukegbuonu@yahoo.com
}

\begin{abstract}
Co-intake-related interactive-synergistic influence of artemether-lumefantrine, AL and monosodium glutamate, MSG that separately mediated oxidative stress could be significant on the kidney actively involved in xenobiotic detoxification and elimination. Thus, influence of AL on rats' kidney histomorphology and antioxidant bioindicators following MSG-challenge was assessed. For 7 days, thirty rats $(n=5)$ were respectively exposed to vehicle (distilled water), therapeutic AL (TAL), high AL (HAL), MSG, MSG plus TAL or MSG plus HAL. Significant $(\mathrm{P}<0.05)$ results comparison showed highest and least $(\mathrm{P}<0.05)$ albumin concentration $(\mathrm{Mg} / \mathrm{dl})$ in TAL-fed $(3.76 \pm 0.33)$ and MSGfed (1.88 \pm 0.70$)$, rats. Total protein concentration (Mg/dl) in MSG-fed (4.04 \pm 2.04$)$ and HAL-fed (4.76 \pm 1.92$)$, rats lowered markedly. Highest glutathione peroxidase activity (IU/L) in TAL-fed (30.74 \pm 12.46$)$ lowered in MSG plus HAL-fed $(20.11 \pm 6.08)$ and MSG-fed (20.33 \pm 4.85$)$, rats. Catalase activity (IU/L) in control was highest $(4.89 \pm 0.26)$ but least $(2.58$ $\pm 1.06)$ in MSG-fed rats. Zinc and Magnesium concentration $(\mathrm{Mg} / \mathrm{dl})$ was respectively highest $(58.99 \pm 5.10)$ and least (3.48 \pm 0.31$)$ in MSG plus HAL-fed but least (18.80 \pm 7.77$)$ and highest $(4.38 \pm 1.67)$ in MSG-fed, rats. Malondialdehyde concentration $(\mu \mathrm{mol} / \mathrm{ml})$ in MSG plus HAL-fed rats $(4.04 \pm 0.67)$ was highest $(\mathrm{P}<0.05)$ and least $(\mathrm{P}<0.05)$ in HAL-fed rats (1.18 \pm 0.11$)$. Differences in superoxide dismutase activity (IU/L) were, however, non-significant $(\mathrm{P}>0.05)$. Rats' kidney photomicrographs $(\mathrm{H} \& \mathrm{E} \times 400)$ revealed normal histo-architecture in control but varied degree of fibroplasias (TAL,HAL- and MSG plus TAL-fed) and necrosis with infiltrations (MSG plus HAL-and MSG-fed), rats. These demonstrated MSG-related adversity and significant modulation response of TAL, unlike HAL, on the rats' kidney histology and studied antioxidant response bio-indicators.
\end{abstract}

\section{DOI:https://dx.doi.org/10.4314/jasem.v25i5.18}

Copyright: Copyright $\odot$ 2021Egbuon et al. This is an open access article distributed under the Creative Commons Attribution License (CCL), which permits unrestricted use, distribution, and reproduction in any medium, provided the original work is properly cited.

Dates: Received: 20 March 2021; Revised: 27 April 2021; Accepted: 07 May 2021

Keywords: Glutathione peroxidase; catalase; superoxide dismutase; malondialdehyde; magnesium; albumin

Malaria caused by malaria parasites as transmitted by mosquitoes is an environmental issue with a significant public health burden in notably developing countries. And, by inducing oxidative stress that damages the causative parasite cell membrane with consequent parasite death, artemether-lumefantrine (AL) combats malaria (Esu, et al., 2014). Generally, monosodium glutamate (MSG) as a choice food flavoring condiment could be ingested along with processed foods. However, oxidative stress contributed significantly to MSG-related toxic effects and eventual cellular and organ-functional damage in animals (Onyema, et al., 2006)particularly nephrotoxic effects as indicated by reduced renal antioxidant defense system markers, including malondialdehyde concentration and activities of superoxide dismutase, SOD, and catalase, CAT(Ortiz, et al., 2006; Paul, et al., 2012).Generally, antioxidant defense mechanisms are mediated by enzymes (SOD, CAT, glutathione peroxidase, GPx) and non-enzymes (malondialdehyde, MDA, albumin, total protein and metal enzyme co-factors, including magnesium and zinc. Earlier studies showed that MSG and AL coadministration affected the MSG-induced effect and could be interactively synergistic (Obi and Egbuonu, 2019; Egbuonu, et al., 2020) which if on the kidney histomorphology and antioxidant defense apparatus could be enormous, hence worrisome. Generally, the kidney aside the liver is responsible for drug metabolism or detoxification and in addition, for the eventual drug metabolites elimination. Thus, kidneys are highly sensitive to xenobiotic-induced toxic insults and need to have an adaptation mechanism via antioxidants-facilitated efficient detoxification apparatus. An antioxidant, which functions as reducing agents hence readily oxidized in cellular reactions, could inhibit or even terminate oxidative chain reactions by preventing or delaying the production of free radicals, removing free radical intermediates, and inhibiting the oxidation of other molecules that could concertedly initiate chain reactions-related cell damage (Mariyamma, et al., 2009).For instance, glutathione peroxidase (GPx) generally protects the organism from oxidative 
damage by either reducing lipid hydroperoxides to their corresponding alcohols or free hydrogen peroxide to water while superoxide dismutase (SOD) repairs and reduces superoxide-related cell damage by promoting the conversion of two superoxide radicals (and other reactive oxygen species, ROS) to hydrogen peroxide and molecular oxygen(Guy, et al., 2011).Zinc, an inhibitor of reduced nicotinamide dinucleotide phosphate, NADPH, oxidase, catalyzes the production of oxygen by using NADPH as the electron donor which results in decreased generation of ROS (Bao, et al., 2010). In addition, zinc acts as a co-factor for important enzymes, including SOD, that ensure efficient functioning of the antioxidant defense system and as an inducer for the generation of metallothionein - which is very rich in cysteine hence an excellent scavenger of hydroxyl radical $\left(\mathrm{OH}^{-}\right.$ ).These warranted this study aimed at determining the changes in kidney histomorphology and some homogenate antioxidant parameters of monosodium glutamate-challenged rats co-treated with artemetherlumefantrine.

\section{MATERIALS AND METHODS}

Sample collection: A brand of monosodium glutamate (99.9 \% purity) was bought from a daily market whereas that of artemether-lumefntrine tablets (80:480 $\mathrm{mg}$ ) was bought from a Pharmacy shop, in Umuahia, Nigeria. Chemicals used in this study were essentially as required and supplied along on purchase of the kits manufactured by Randox Limited hence were used without further purification. Formalin $(10 \%)$ used for preserving the kidney prior to processing for histological examination were sourced from competent chemical dealers in Umuahia, Nigeria.

Ethical approval: In compliance with the norms of bioethics, the general ethical principles/guidelines emphasizing the protection and humane handling of animals, including vertebrates, used for experimental and other scientific purposes as approved/recommended by the Biochemistry Departmental Ethical Committee of Michael Okpara University of Agriculture Umudike, Nigeria were fully followed throughout the experimentation (acclimatization and exposure periods).

Animal acclimatization and exposure: The thirty (30) male albino Wistar rats used in this study weighed 80 - $120 \mathrm{~g}$ and, after one week acclimatization, were randomly assigned into six groups of five (5) rats each and housed in metal cages under standardized laboratory conditions $\left(25^{\circ} \mathrm{C}, 12\right.$-h daylight/ 12-h dark cycle and tropical humidity). For 7 days, rats in the various groups were respectively exposed freely to feed (commercial growers mash, product of Top feed limited, Sapele, Nigeria) and portable tap water in addition to vehicle, distilled water, (Group A), therapeutic AL dose, TAL, (Group B), high AL dose, HAL (Group C), intoxicating MSG dose (Group D), MSG plus TAL (Group E), or MSG plus HAL (Group F). The exposure was through gavages-assisted oral cavity. Artemether-lumefantrine overdose was calculated as therapeutic dose of AL for $70 \mathrm{~kg}$ man multiplied by 5 . The administration of artemetherlumefantrine was twice each day after $8 \mathrm{hrs}$ interval according to the prescription dosage for a $70 \mathrm{~kg}$ adult and given in rats weight per volume (w/v) which was prepared by dissolving adult dose (1 tablet containing $80: 480 \mathrm{mg}$ ) of artemether-lumefantrine in $100 \mathrm{ml}$ of distilled water as described in recent reports [5,6]. Rats' intoxication with MSG was achieved at 8000 $\mathrm{mg} / \mathrm{kg}$ body weight and by daily exposure according to Mariyamma, et al. (2009) with slight modification (for 7 instead of 20 days) and as supported by other studies (Egbuonu and Oriji, 2017; Mbah and Egbuonu, 2017a; Mbah and Egbuonu, 2017b; Egbuonu and Ekwuribe, 2017; Egbuonu and Ejike, 2017). After exposure on the $7^{\text {th }}$ day, the animals were starved overnight, sacrificed by cervical dislocation and dissected using surgical blades. The kidneys of the respective rat were promptly excised and placed in separately labeled containers. One part was rinsed in iced-cold sucrose, and a $10 \% \mathrm{w} / \mathrm{v}$ homogenate was prepared from it using $0.15 \mathrm{M} \mathrm{KCl}$ as buffer to obtain the supernatant sample after centrifugation (Mbah and Egbuonu, 2017b). The other part was preserved in a tube containing formalin prior to sectioning for histological evaluation.

Determination of Catalase activity: Catalase (CAT. EC 1.11.1.6) activity (IU/L) in the kidney homogenate of the rats was determined by the method as described by Sinha (1972)based on the principle that dichromate in acetic acid was reduced to chromic acetate when heated in the presence of hydrogen peroxide $\left(\mathrm{H}_{2} \mathrm{O}_{2}\right)$ with the formation of per chromic acid as an unstable intermediate.

Determination of Glutathione Peroxidase activity: Glutathione peroxidase (GPx EC 1.11.1.9) activity (IU/L) was determined by the method of Paglia and Valentine (1967) based on the principle that glutathione peroxidase catalyzes the oxidation of glutathione (GSH).

Determination of Superoxide Dismutase activity: Superoxide dismutase (SOD EC 1.15.1.1) activity (IU/L) was determined using the method of Xin, et al.(1991).This was based on the principle that SOD enzyme catalyzes the conversion of two superoxides radicals into the less toxic hydrogen peroxide and 
molecular oxygen in reactions that inhibit nitroblue tetrazolium (NBT) reduction.

Determination of Lipid Peroxidation product, Malondialdehyde, concentration: Lipid peroxidation was determined by the method of Wallin, et al. (1993) as described earlier (Egbuonu and Ezeanyika, 2012). This was based on spectrophotometric estimation of the level of the lipid peroxidation product, malondialdehyde (MDA) and on the principle that lipid degradation occurs with the formation of malondialdehyde, MDA, which reacts with thiobarbituric acid to form a red or pink coloured complex which in acid solution absorbs maximally at $532 \mathrm{~nm}$.

Determination of Magnesium concentration: Magnesium concentration in the kidney homogenate samples was estimated by the method of Farrell (1984) based on the principle that magnesium reacts with Calmagite in alkaline medium/solution (with selective removal or reduction of calcium interference from the samples (Tesfald, et al., 2004)) forming apurplecoloured complex with colour intensity proportional to the magnesium concentration in the sample that can be measured using a spectrophotometer.

Determination of Zinc concentration: Zinc concentration in the samples was estimated by the method of Johnsen and Eliasson (1987). This was based on the principle that zinc forms a red coloured chelate complex on reacting with 2-(5-Brom-2pyridylazo)-5-(N-propyl-N-sulfo-propylamino)phenol and the resultant absorbance which is proportional to the concentration of total zinc in the sample could be measured spectrophotometrically.

Determination of Total protein concentration: Total protein concentration $(\mathrm{Mg} / \mathrm{dl})$ in the rats' kidney homogenate was determined with a protein assay kit (Sigma Diagnostics, P 5656, Sigma, MO, USA) as in the enclosed direction based on Buiret method and the principle that at alkaline $\mathrm{pH} 7.0$, proteins form a stable complex with copper II ion, $\mathrm{Cu}^{2+}$, which could be measured spectrophotometrically at 546 .

Determination of Albumin concentration: Albumin concentration $(\mathrm{Mg} / \mathrm{dl})$ in the rats' kidney homogenate was estimated using Bromocresol green (BCG) according to Doumaset al. (1971) as described recently (Egbuonu and Ezeanyika, 2013). Photomicrographs of the kidney sections after fixation were with a Motic ${ }^{\mathrm{TM}} 9.0$ megapixels compound light microscope camera at magnification value of $\times 400$ as previously reported (Mbah and Egbuonu, 2017b).
Data Analysis: The numeric data as obtained in this study were subjected to one way analysis of variance (ANOVA) to test for difference in mean among all the groups. Statistical package for social sciences (SPSS) version 20.0 was used Reliable difference was accepted as significant at P-value of $<0.05$ based on Duncan's multiple range tests. Results were expressed as mean \pm standard deviation, $\mathrm{SD}($ mean $\pm \mathrm{SD})$.

\section{RESULTS AND DISCUSSION}

The result showed that, compared to control and other groups, albumin concentration $(\mathrm{Mg} / \mathrm{dl})$ in TAL-fed $(3.76 \pm 0.33)$ and MSG-fed $(1.88 \pm 0.70)$ rats was, respectively, highest and least $(\mathrm{P}<0.05)$. Total protein concentration $(\mathrm{Mg} / \mathrm{dl})$ in MSG-fed $(4.04 \pm 2.04)$ and HAL-fed $(4.76 \pm 1.92)$ rats lowered markedly $(\mathrm{P}<0.05)$ (Table 1).The glutathione peroxidase activity (IU/L) was highest $(\mathrm{P}<0.05)$ in TAL-fed rats $(30.74 \pm 12.46)$ but similarly lowered $(\mathrm{P}<0.05)$ in MSG plus HAL-fed $(20.11 \pm 6.08)$ and MSG-fed $(20.33 \pm 4.85)$ rats. Catalase activity (IU/L) in control rats was highest $(4.89 \pm 0.26)$ followed by that in TAL-fed rats $(4.27 \pm$ $1.30)$ and MSG plus TAL-fed rats $(4.07 \pm 0.82)$ while the least $(2.58 \pm 1.06)$ was in MSG-fed rats. Differences in superoxide dismutase activity (IU/L) in the various rat groups were non-significant $(\mathrm{P}>0.05)$ (Table 2).

Zinc concentration $(\mathrm{Mg} / \mathrm{dl})$ was highest in MSG plus HAL-fed (58.99 \pm 5.10$)$, least in MSG-fed $(18.80 \pm 7.77)$ but similar in HAL-fed $(53.80 \pm 5.04)$ and control (54.23 \pm 7.93$)$ rats. Magnesium concentration $(\mathrm{Mg} / \mathrm{dl})$ was least $(3.48 \pm 0.31)$ in MSG plus HAL-fed rats followed by that in TAL-fed (3.74 \pm 0.33$)$, HALfed $(3.78 \pm 1.88)$ and MSG-fed $(4.38 \pm 1.67)$ or MSG plus TAL-fed $(4.38 \pm 0.49)$ rats. Malondialdehyde concentration $(\mu \mathrm{mol} / \mathrm{ml})$ in MSG plus HAL-fed rats $(4.04 \pm 0.67)$ was highest $(\mathrm{P}<0.05)$ while that in HALfed rats $(1.18 \pm 0.11)$ was least $(\mathrm{P}<0.05)$ followed by that in MSG-fed rats $(1.76 \pm 0.96)$.

Rats' kidney photomicrographs $(\mathrm{H} \& \mathrm{E} \times 400)$ revealed normal histo-architecture in control rats but fibroplasias (TAL-, HAL- and MSG plus TAL-fed rats) and necrosis with infiltrations (MSG plus HALand MSG-fed rats) (Table 3).Rats' kidney photomicrographs $(\mathrm{H} \& \mathrm{E} \times 400)$ revealed normal histo-architecture in control rats (Figure 1) but fibroplasias (arrow heads) that were diffused, mild and moderate, respectively in TAL-, HAL- and MSG plus TAL-fed rats (Figures 2, 3 and 5) and necrosis with infiltrations that were marked and diffused, respectively in MSG-and MSG plus HAL-fed rats (Figures 4 and 6). 
Table 1: Changes in albumin and total protein (TP) concentration in the kidney homogenate of normal and monosodium glutamateintoxicated rats co-treated with artemether-lumefantrine

\begin{tabular}{lll}
\hline Groups & Albumin $(\mathrm{Mg} / \mathrm{dl})$ & $\mathrm{TP}(\mathrm{Mg} / \mathrm{dl})$ \\
\hline Group A (Control) & $3.70 \pm 0.68$ & $6.82 \pm 0.19$ \\
Group B (TAL-fed) & $3.76 \pm 0.33$ & $5.80 \pm 0.55$ \\
Group C (HAL-fed) & $2.30 \pm 1.23$ & $4.76 \pm 1.92$ \\
Group D (MSG-fed) & $1.88 \pm 0.70$ & $4.04 \pm 2.04$ \\
GroupE (MSG+TAL-fed) & $3.70 \pm 0.31$ & $5.84 \pm 0.37$ \\
Group F (MSG + HAL-fed) & $3.46 \pm 0.42$ & $5.90 \pm 0.75$ \\
\hline a \pm SDfor $n=5$ rats. Difference in mean was accepted as statistically significant at $P<0.05$
\end{tabular}

Table 2: Changes in glutathione peroxidase (GPx), catalase (CAT) and superoxide dismutase (SOD) activity in the kidney homogenate of normal and monosodium glutamate-intoxicated rats co-treated with artemether-lumefantrine

\begin{tabular}{llll}
\hline Groups & Gpx (IU/L) & CAT (IU/L) & SOD (IU/L) \\
\hline Group A (Control) & $26.89 \pm 12.51$ & $4.89 \pm 0.26$ & $11.33 \pm 0.07$ \\
Group B (TAL-fed) & $30.74 \pm 12.46$ & $4.27 \pm 1.30$ & $10.54 \pm 0.03$ \\
Group C (HAL-fed) & $20.58 \pm 11.89$ & $3.78 \pm 2.13$ & $11.35 \pm 0.15$ \\
Group D (MSG-fed) & $20.33 \pm 4.85$ & $2.58 \pm 1.06$ & $10.65 \pm 0.99$ \\
Group E (MSG+TAL-fed) & $22.81 \pm 13.89$ & $4.07 \pm 0.82$ & $11.30 \pm 0.35$ \\
Group F (MSG + HAL-fed) & $20.11 \pm 6.08$ & $3.14 \pm 0.44$ & $10.99 \pm 0.43$ \\
\hline mean $\pm S D$ for $n=5$ rats. Difference in mean was accepted as statistically significant at $P<0.05$
\end{tabular}

Table 3: Changes in zinc, magnesium and Malondialdehyde (MDA) concentration in the kidney homogenate of normal and monosodium glutamate-intoxicated rats co-treated with artemether-lumefantrine

\begin{tabular}{llll}
\multicolumn{4}{c}{ glutamate-intoxicated rats co-treated with artemether-lumefantrine } \\
\hline Groups & Zinc $(\mathrm{Mg} / \mathrm{dl})$ & Magnesium $(\mathrm{Mg} / \mathrm{dl})$ & $\mathrm{MDA}(\mu \mathrm{mol} / \mathrm{ml})$ \\
\hline Group A (Control) & $54.23 \pm 7.93$ & $5.29 \pm 0.81$ & $3.74 \pm 0.99$ \\
Group B (TAL-fed) & $48.07 \pm 7.69$ & $3.74 \pm 0.33$ & $3.88 \pm 0.71$ \\
Group C (HAL-fed) & $53.80 \pm 5.04$ & $3.78 \pm 1.88$ & $1.18 \pm 0.11$ \\
Group D (MSG-fed) & $18.80 \pm 7.77$ & $4.38 \pm 1.67$ & $1.76 \pm 0.96$ \\
Group E (MSG+TAL-fed) & $34.63 \pm 6.73$ & $4.38 \pm 0.49$ & $3.10 \pm 0.35$ \\
Group F (MSG + HAL-fed) & $58.99 \pm 5.10$ & $3.48 \pm 0.31$ & $4.04 \pm 0.67$ \\
Values of mean $\pm S D$ for $n=5$ rats. Difference in mean was accepted as statistically significant at $P<0.05$
\end{tabular}

Changes in kidney histomorphology and some homogenate antioxidant parameters of monosodium glutamate-challenged rats co-treated with artemetherlumefantrine, AL, were evaluated by standard methods involving estimation of relevant antioxidant bio-indicators. In particular, albumin earlier linked with antioxidant properties (Quinlan, et al., 2004; Guy, et al., 2011) due to its multiple ligand-binding capacities and free radical trapping properties (Oettl and Stauberb, 2007) was determined. And, compared to other groups, albumin concentration in TAL-fed and MSG-fed rats was, respectively, highest and least $(\mathrm{P}<0.05)$ implying that AL particularly at therapeutic dose could improve the albumin anabolism and biofunction while significantly reversing MSG-induced reduction in albumin synthesis and reduction-related dysfunctions. In contrast, the reduction in albumin concentration in the MSG-fed rats could be attributed to antioxidant response-related consequential albumin catabolism to provide sulfur-containing amino acids for glutathione, GSH, synthesis in the apparently MSG-related oxidative stress in the rats. Albumin protects cells from oxidative stress by up-modulation of cellular GSH level via its (albumin) catabolism to provide sulfur-containing amino acids required for the synthesis of thiol-containing molecules including GSH (Turel, et al., 2008). Similarly, total protein concentration in MSG-fed and HAL-fed rats lowered markedly $(\mathrm{P}<0.05)$, which suggests adverse influence of MSG intoxication-related diminution of total protein synthesis cum bio-functions. This could be via, most likely, enhanced protein catabolism in apparent support of the observation of this study on albumin concentration and suggestions thereto.

Glutathione peroxidase activity was highest $(\mathrm{P}<0.05)$ in TAL-fed rats but lowered $(\mathrm{P}<0.05)$ in $\mathrm{MSG}$ plus HAL-fed as in MSG-fed, rats. The result could be a pointer that AL particularly at therapeutic dose could improve, but without exerting significant reversion of MSG-induced diminution of, the glutathione preoxidase-related antioxidant defense activity in, especially MSG plus HAL-fed rats' kidney. Glutathione peroxidase (GPx) via its antioxidant response activity protects organisms from oxidative cell damage (Lubos, et al., 1997) by reducing lipid hydroperoxides to their corresponding alcohols or free hydrogen peroxide to water (reduced free hydrogen peroxide) (Guy, et al., 2011). Lowered Gpx activities indicated impaired antioxidant protection leading to oxidative damage (Chabory, et al., 2009). And, MSG induction of oxidative stress notably at $8000 \mathrm{mg} / \mathrm{Kg}$ body weight has been reported (Mariyamma, et al., 2009; Egbuonu and Ejike, 2017; Singh and Ahluwalia, 2003; Diniz, et al., 2004; Pavlovic, et al., 2002) thus explaining the observation on GPx activity in the rats' kidney homogenate. 
Catalase enzyme protects the cell from the toxic effects of hydrogen peroxide by promoting the catabolism of hydrogen peroxide into molecular oxygen and water (Egbuonu and Ejike, 2017). In this study, catalase activity in control rats was highest followed by that in TAL-fed rats and MSG plus TALfed rats while the least was in MSG-fed rats, suggesting modulation response of therapeutic dose of AL on MSG-related adversity on the catalase activity and bio-functions in the rats' kidney. A significantly reduced catalase activity in the kidney of animals following MSG administration was previously reported (Paul, et al., 2012).

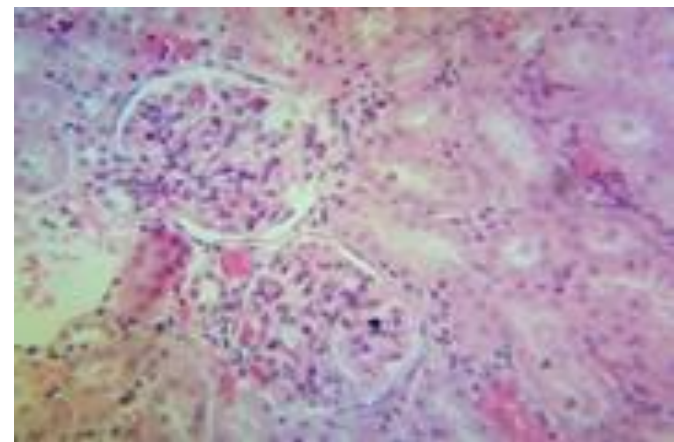

Fig 1: Photomicrograph of Group A (control) rats' kidney section showing normal histo-architecture of renal corpuscles (RC) and renal tubules $(\mathrm{RT}) . \mathrm{H} \& \mathrm{E} \times 400$.

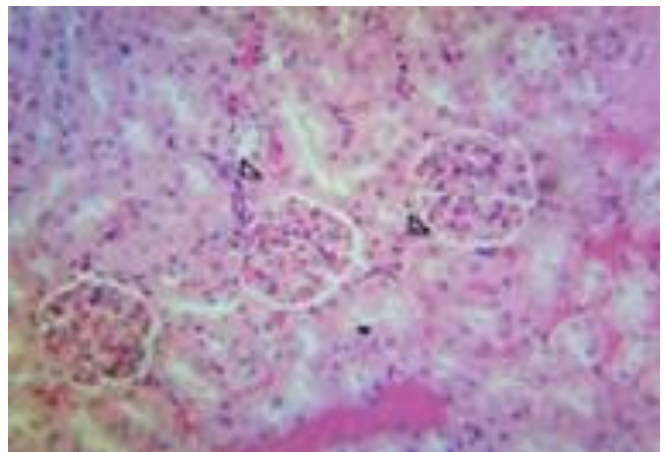

Fig 2: Photomicrograph of Group B (TAL-fed) rats' kidney section showing diffused peritubular fibroplasias (Arrow heads). H\&E, $\times$ 400

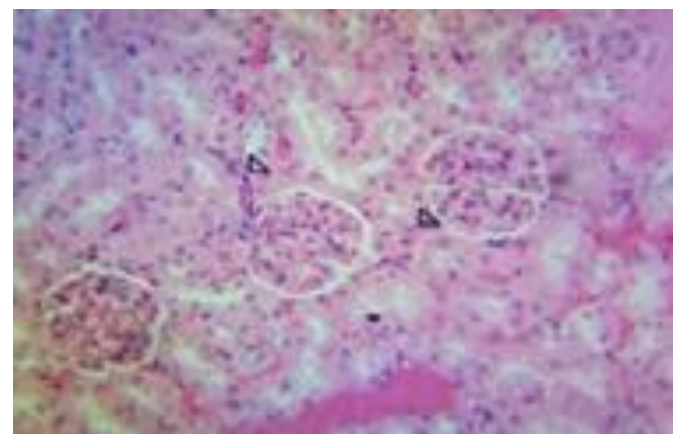

Fig 3: Photomicrograph of Group C (HAL-fed) rats' kidney section showing fibrinous exudate obliterating the bowman's space and mild fibroplasias (Arrow heads). There was also an area of necrotic foci. $\mathrm{H} \& \mathrm{E}, \times 400$.

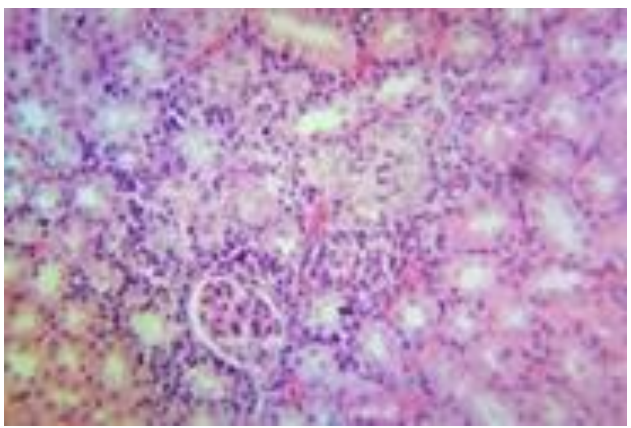

Fig 4: Photomicrograph of Group D (MSG-fed) rats' kidney section showing marked focal area of tubular necrosis with mononuclear cellular infiltrations. H\&E, $\times 400$.

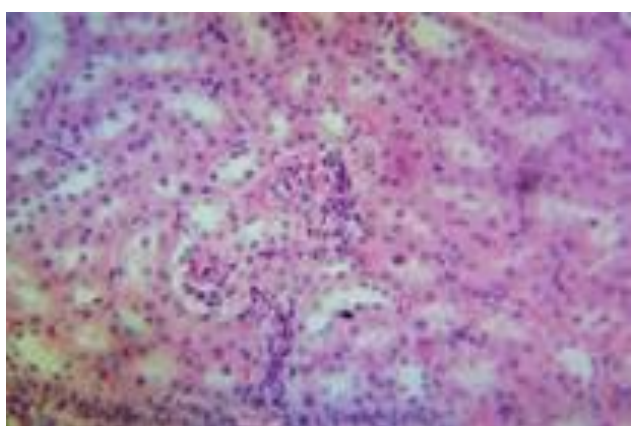

Fig 5: Photomicrograph of Group E (MSG + TAL-fed) of rats' kidney section showing moderate fibroplasia with mild mononuclear cellular infiltrations. $\mathrm{H} \& \mathrm{E}, \times 400$

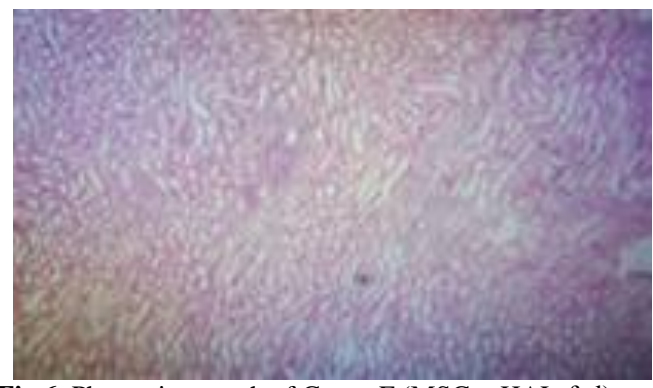

Fig 6: Photomicrograph of Group F (MSG + HAL-fed) rats'

kidney section showing diffused areas of tubular necrosis with mononuclear cellular infiltrations. $\mathrm{H} \& \mathrm{E}, \times 400$

And, the formation of reactive oxygen species, ROS, in the kidney exposed to MSG was strongly associated with nephrotoxic effects leading to cellular and organfunctional damage in experimental animals (Ortiz, et al., 2006).. Superoxide dismutase (SOD) repairs and reduces superoxide-related cell damage by promoting the conversion of two superoxide radicals (and other reactive oxygen species, ROS) to hydrogen peroxide and molecular oxygen (Guy, et al., 2011). Differences in superoxide dismutase activity in the various rat groups were non-significant $(\mathrm{P}>0.05)$, hence essentially similar and negligible. This suggests unclear-cut SOD activity response in the various rats' kidney due possibly to the preclusion of SOD activity among the first line of antioxidant defense response in the rats' kidney. SOD is considered the first line of 
defense against the deleterious effect of reactive oxygen radical species by catalyzing the dismutation of superoxide radicals to hydrogen peroxide and oxygen (Egbuonu and Ejike, 2017). Malondialdehyde (MDA) results from lipid peroxidation (LPO) of polyunsaturated fatty acids (Davey, et al., 2005), hence serves as a good bio-indicator of oxidative stress induction. Malondialdehyde concentration in MSG plus HAL-fed rats was highest $(\mathrm{P}<0.05)$ while that in HAL-fed rats was least $(\mathrm{P}<0.05)$ followed by that in MSG-fed rats. This indicated possible synergistic interaction of intoxicating dose of $\mathrm{AL}$ and $\mathrm{MSG}$ for the study duration, which could elicit a spiked reversal of apparent toleration of either (AL or MSG) alone, on the rats' kidney MDA metabolism and bio-functions, warranting a follow up study.

Zinc, an inhibitor of reduced nicotinamide dinucleotide phosphate, NADPH, oxidase, catalyzes the production of oxygen by using NADPH as the electron donor which results in decreased generation of ROS. In addition, zinc acts as a co-factor for important enzymes, including SOD, that ensure efficient functioning of the antioxidant defense system, and as an inducer for the generation of cysteine-rich metallothionein- an excellent scavenger of hydroxyl radical $\left(\mathrm{OH}^{-}\right)(\mathrm{Bao}$, et al., 2010). Zinc concentration was highest in MSG plus HAL-fed, least in MSG-fed but similar in HAL-fed and control rats, suggesting that AL particularly at high dose could improve the zinc anabolism and bio-function while significantly reversing MSG-induced reduction in zinc synthesis and reduction-related dysfunctions. Magnesiumconcentration strongly associated withreduced cum oxidized glutathione, GSH/GSSG, concentration balance (Anastasia, et al., 2016) as well as the activation of the renin-angiotensin system that induces oxidative stress (Rayssiguier, et al., 2010). Thus, Mg concentration could serve as a bio-indicator of oxidative stress. Magnesium concentration was least in MSG plus HAL-fed rats followed by that in TAL-fed, HAL-fed and MSG-fed or MSG plus TALfed, rats. This may be indicating marked adversity on the magnesium metabolism and bio-functions in rats' kidney MSG plus high AL-exposed rats.

Histomorphologic assessment of organs complements results of biochemical indicators of organs status and bio-functions in determining the extent of organ responses to agent-induced toxic influence [7, 36-39). Rats' kidney photomicrographs $(\mathrm{H} \& \mathrm{E} \times 400)$ revealed normal histo-architecture in control rats (Figure 1) but fibroplasias that were diffused, mild and moderate, respectively in TAL-, HAL- and MSG plus TAL-fed rats (Figures 2, 3 and 5) and necrosis with infiltrations that were marked and diffused, respectively in MSG- and MSG plus HAL-fed rats (Figures 4 and 6). Similar findings following MSG exposure in rats were observed in earlier studies (Inuwa, et al., 2011; Tawfik and Al-Badr, 2012; Contini, et al., 2012; Onaolapo, et al., 2013). The tubular necrosis with mononuclear cellular infiltration as observed in MSG-fed rats (Group D) may have resulted as a response to severe toxic injury while fibroplasia noted in TAL-, HALand MSG plus TAL-fed rats indicated further annealing capacity of the exposure (Kehrel, 2003)in apparent conformity with the observation on the determined antioxidant bio-indicators of the rats' kidney homogenate. In all, these (the observation on the determined biochemical parameters and histological assessment) suggested that therapeutic artemether-lumefantrine dose, unlike that of artemether-lumefantrine overdose, modulated monosodium glutamate-related adversity on rats' kidney histology and some homogenate antioxidant response bio-indicators. It is important to point out that MSG-intoxication resulted in oxidative stress (Mariyamma, et al., 2009) and reportedly manifested with an increase in most of the studied antioxidant bioindicators but in the rats' serum (Egbuonu and Ejike, 2017). This in juxtaposition with the present observation while seemingly quite intriguing, probably suggests differing animal sample-specific oxidative stress response from MSG overdose, warranting further detailed investigations.

Conclusion: Thus, the study demonstrated MSGrelated adversity and significant modulation response of artemether-lumefantrine therapeutic dose, TAL, unlike artemether-lumefantrine overdose, HAL, on the rats' kidney histology and studied antioxidant response bio-indicators.The intriguing apparent differing animal sample-specific oxidative stress response from MSG overdose muted herein, deserves follow up, hence recommended as it could throw light on the hitherto obscure basis for MSG toxicity.

\section{REFERENCES}

Anastasia, AZ; Maria, VK; Igor, NI; Alexander, AS (2016). Magnesium deficiency and oxidative stress: an update. Biomed. 6(4): 8-14

Bao, B; Prasad, AS; Beck, FWJ; Fitzgerald, JT; Snell, D;Bao, GW (2010). Zinc decreases C-reactive protein, lipid peroxidation, and implication of zinc as an atheroprotective agent. Am J Clin Nutr. 91(6): 16341641

Chabory, E; Damon, C; Lenoir, A; Kauselmann, G; Kern, H; Zevnik, B; Barrel, C; Saez, F; Cadet, R; HenryBerger, J; School, M; Gottwald, U; Habenicht, U; Drevet, JR; Vernetm, P (2009). Epididymis seleno- 
independent glutathione peroxidase 5 maintains sperm DNA integrity in mice. J Clin Invest. 119(7): 20742085

Contini, MDC; Millen, N;Riera, L;Mahieu, S (2012). Kidney and liver functions and stress oxidative markers of monosodium glutamate induced obese rats. Food and Public Health. 2(5):168-177

Davey, MW;Stals, E;Panis, B;Keulemans, J;Swennen, RL (2005). High-throughput determination of malondialdehyde in plant tissues. Anal Biochem. 347(2): 201-207

Diniz, YS;Cicogna, AC; Padovani, CR; Santana, LS; Faine, LA; Novelli, EL (2004). Diets rich in saturated and polyunsaturated fatty acids: metabolic shifting and cardiac health. Nutr. 20(2): 230-234

Doumas, BT; Watson, WA; Biggs, HG (1971). Albumin standard and the measurement of serum albumin with bromcresol green. Clin Chim Acta. 31(1): 87-96

Egbuonu, ACC;Ejike, GE (2017). Effect of pulverized Mangifera indica (mango) seed kernel on monosodium glutamate-intoxicated rats' serum antioxidant capacity, brain function and histology. EC Pharmacol Toxicol. 4(6): 228-243

Egbuonu, ACC; Ejikeme, PM; Ezeanyika, LUS; Obidoa, O (2013c). Combined oral arginine and monosodium glutamate exposure induces adverse response on the prostate function and testis histology of rats. $\mathrm{Br} J$ Pharm Res. 3(2): 247-258

Egbuonu, ACC; Ekwuribe, GA (2017). Pulverized Mangifera indica (mango) seed-kernel modulated serum lipid profile in monosodium glutamatechallenged rats. J Applied Biotech. 5(2): 72-87

Egbuonu, ACC; Ezeanyika, LUS (2012). Effect of Larginine on selected markers of metabolic syndrome related to oxidative stress, glucose metabolism and nitric oxide synthesis in female Wistar albino rats. Int Res J Biochem Bioinform. 2(8): 186-192

Egbuonu, ACC; Ezeanyika, LUS (2013). L-arginine exposure improves renal function markers of metabolic syndrome in female rats. Am J Biochem Mol Biol. 3(1): $50-60$

Egbuonu, ACC; Ezeanyika, LUS; Ejikeme, PM; Obidoa, O (2010). Histomorphologic alterations in the liver of male Wistar rats treated with ${ }_{\mathrm{L}}$-arginine, glutamate and monosodium glutamate. Res J Environ Toxicol. 4(4): 205-213

Egbuonu, ACC; Ezeanyika, LUS; Ijeh II (2013b). Alterations in the liver histology and markers of metabolic syndrome associated with inflammation and liver damage in L-arginine exposed female Wistar albino rats. Pak J Biol Sci. 16(10): 469-476

Egbuonu, ACC; Ijeh, II; Ezeanyika, LUS; Obidoa O (2013a). Influence of ${ }_{L}$-arginine on the heart histology and function markers of metabolic syndrome in female Wistar albino rats. J Med Sci. 13(4): 276-282

Egbuonu, ACC; Obi, E; Nwuke, CP; Simon, CU; Oleghibe, JU; Ezenwafor, NR; Chukwu, EM (2020). Monosodium glutamate plus artemether-lumefantrine overdose altered malondialdehyde, total protein and albumin concentration in rats. Adv. J Grad Res. 7(1): 70-79

Egbuonu, ACC; Oriji SA (2017). Pulverized Mangifera indica (mango) seed kernel mitigated monosodium glutamate-intoxicated rats' kidney histology and biofunctions. J Nutrition Health Food Sci. 5(2): 1-7

Esu, E; Effa, EE; Opie, ON; Uwaoma, A; Meremikwu, MM (2014). Artemether for severe malaria. The Cochrane Database Syst. Rev. 9(CD010678): 1-85

Farrell, EC (1984). Magnesium. In Kaplan Aet al. edited Clinical Chemistry. The C.V. Mosby Co. St Louis. Toronto. Princeton 1065-1069

Guy, R; Griuncelli, M; Loridon, C; Bourlet, T; Illouz, E; Benmaadi, A (2011). Modulation of oxidative stress and micro inflamatory status by colloids in refractory dialytic hypotension. BMC Nephrol. 12(58): 1-9

Inuwa, HM; Aina, VO; Baba, G; Aimola, I; Leehman, J (2011). Determination of nephrotoxicity and hepatoxicity of monosodium glutamate (MSG) consumption. Br J Pharmacol Toxicol. 2(3):148-153

Johnsen, O; Eliasson, R (1987). Evaluation of a commercially available kit for the colorimetric determination of zinc in human seminal plasma. Int $J$ Androl. 10(2): 435-440

Kehrel, BE (2003). Blood platelets: biochemistry and physiology. Hamostaseologie. 23(4): 149-158.

Lubos, E; Loscalzo, J; Handy, DE (2011). Glutathione peroxidase-1 in health and disease: from molecular mechanisms to therapeutic opportunities. Antioxid Redox Signal. 15(7):1957-1997.

Mariyamma, TM; Sujatha, KS; George, S (2009). Protective effect of Piper longum Linn. on monosodium glutamate induced oxidative stress in rats. Indian J Exp. Biol. 47(3):186-192

Mbah, UO; Egbuonu, ACC (2017a). Ethanolic extract of Solanum melongena Linn fruit mitigated monosodium 
glutamate-induced oxidative stress. Int J Biochem Res and Rev. 18(2): 1-8

Mbah, UO; Egbuonu, ACC (2017b). Ameliorative potentials of eggplant (Solanum melongena Linn) fruit ethanolic extract on monosodium glutamateintoxicated rats' lipid profile, haematology and heart histology. Int J Biochem Res and Rev. 18(3): 1-10

Obi, E; Egbuonu, ACC (2019). Changes in the liver histomorphology, catalase and glutathione peroxidase activity in the serum and liver homogenate of normal and monosodium glutamate-intoxicated rats co-treated with artemether-lumefantrine. Int J MolBiol Open Access, IJMBOA. 4(2): 67-73

Onaolapo, AY; Onaolapo, OJ; Mosaku, TJ; Akanji, O; Abiodun, O (2013). A histological study of the hepatic and renal effects of sub-chronic low dose oral monosodium glutamate in Swiss albino mice. $\mathrm{Br} \mathrm{J} \mathrm{Med}$ \&Med Res. 3(2): 294-306

Onyema, OO; Farombi, EO; Emerole, G; Ukoha, AI; Onyeze, GO (2006). Effect of vitamin E on monosodium glutamate induced hepatotoxicity and oxidative stress in rats. Indian J Biochem Biophys. 43(1): $20-24$

Ortiz, GG; Bitzer-Quintero, OK; Zarate, CB; RodriguezReynoso, S; Larios-Arceo, F; Velazquez-Brizuela, IE (2006). Monosodium glutamate-induced damage in liver and kidney: a morphological and biochemical approach. Biomed Pharmacother. 60(2): 86-91

Paglia, DE; Valentine, WN (1967).Studies on the quantitative and qualitative characterization of erythrocyte glutathione peroxidase. J Lab Clin Med. 70(1): $158-169$

Paul, MV; Abhilash, M; Varghese, MV; Alex, M; Nair, RH (2012). Protective effects of alpha-tocopherol against oxidative stress related to nephrotoxicity by monosodium glutamate in rats. Toxicol Mech Methods. 22(8):625-630.

Pavlovic, D; Tamburic, V; Stojanovic, I; Kocic, G; Jevtovic, T; Dordevic, V (2002). Oxidative stress as markers of positive symptoms in schizophrenia. Med \& Biol. 9(2):157-161
Oettl, K; Stauberb, RE (2007). Physiological and pathological changes in the redox state of human serum albumin critically influence its binding properties. $\mathrm{Br} J$ Pharmacol. 15(5): 580-590

Quinlan, GJ; Mumby, S; Martin, GS; Bernard, GR; Gutteridge, JM; Evans, TW (2004). Albumin influences total plasma antioxidant capacity favorably in patients with acute lung injury. Crit Care Med. 32(3): 755-759

Rayssiguier, Y; Libako, P; Nowacki, W; Rock, E (2010). Magnesium deficiency and metabolic syndrome: stress and inflammation may reflect calcium activation. Magnes Res. 23(2): 73-80

Singh, K; Ahluwalia, P (2003).. Studies on the effect of Monosodium Glutamate (MSG) administration on some antioxidant enzymes in the arterial tissue of adult male mice. J Nutr Sci. Vitaminol. 49(2): 145-148

Sinha, KA (1972). Colorimetric assay of catalase. $J$ Biochem. 47(2): 389 -389

Tawfik, M; Al-Badr, N (2012). Adverse effects of monosodium glutamate on liver and kidney functions in adult rats and potential protective effect of vitamins C and E. Food Nutr Sci. 3(5): 651-659

Tesfald, ZO; van Staden, JF; Stefan, RI (2004). Spectrophotometric determination of magnesium in pharmaceutical preparations by cost-effective sequential injection analysis. Talanta. 64(4): 981-988

Turel, L; Botti, H; Carballal, S; Ferrer-Suera, G; Souza, JM; Duran, R; Freeman, BB; Radi, R; Alvarex, B (2008). Reactivity of sulfenic acid in human serum albumin. Biochem. 47(1): 358-367

Wallin, B; Rosengren, B; Shertzer, HG; Cameyo, G (1993). Lipoprotein oxidation and measurement of TBARS formation in a single micro-titer plate: Its use for evaluation of antioxidants. Anal Biochem. 208(1): $10-15$.

Xin, JS; Guo, JC; Zhu, HQ; Song, XX (1991). An assay for superoxide dismutase in mammalian tissue homogenates. Anal Biochem. 179: 8-18. 